\title{
Sexually Transmitted Infections (STI) in Men Who Have Sex with Men (MSM)
}

\author{
Göran Bratt $^{*}, 1$, Magnus Edlund ${ }^{1}$, Malin Cullberg ${ }^{2}$, Bo Hejdeman ${ }^{1}$, Anders Blaxhult ${ }^{1}$ and \\ Lars E. Eriksson ${ }^{1,3}$
}

\author{
${ }^{I}$ Department of Clinical Science and Education, Karolinska Institute, Södersjukhuset, Unit: Venhälsan, Stockholm, \\ Sweden \\ ${ }^{2}$ Department of Dermatology and Venereology, Karolinska University Hospital, Stockholm, Sweden \\ ${ }^{3}$ Division of Nursing, Department of Neurobiology, Care Sciences and Society, Karolinska Institute, Södersjukhuset, \\ Unit: Venhälsan, Stockholm, Sweden
}

\begin{abstract}
The impact of increasingly efficient antiretroviral therapy (ART) on survival and general well-being has contributed to a "business as usual" attitude to sex among men who have sex with men (MSM). There has been a recent marked increase of sexually transmitted infections (STI) including syphilis, LGV and Hepatits C among MSM. STIs located in the oral cavity or rectum are asymptomatic in over $80 \%$ and $50 \%$, respectively and these sites must be seen as important reservoirs. On the other hand severe proctitis may be mistreated as inflammatory bowel disease without adequate medical history and testing. Due to the reappearance of syphilis, all genital ulcers, non-itching exanthema and severe disease symptoms (e.g. fever, fatigue, lymphadenopathy, hepato-splenomegaly, increased liver enzymes, neurological and ophthalmologic symptoms without other explanations) should lead to testing for syphilis. There is a marked association between STIs and HIV. Syphilis, LGV and Hepatits C are strongly overrepresented in HIV positive MSM, while gonorrhoea, LGV and syphilis increase the HIV susceptibility. Syphilis leads to increased viral load in HIV positive. The major risk factors for Hepatitis B are number of sex partners and receptive anal intercourse. High grade Human Papilloma Virus (HPV) anal lesions can progress to cancer. There is a 30 fold increase risk for anal cancer among MSM, a risk that is doubled in HIV infection, making anal cancer one of the most common non-AIDS tumours. All MSM should be offered Hepatitis A and B vaccination and the inclusion of boys in HPV vaccination programs must be considered. The aim of this article is to describe asymptomatic and symptomatic bacterial and viral STIs of the oral cavity, penis/urethra and rectum and the sexually transmittable viral Hepatitis and HIV in MSM and to inspire the medical establishment to adhere to testing guidelines in this group. This article is built on a review of published findings, the presentation of own data on Gonorrhoea and chlamydia and our own experience in treating all STIs including HIV in MSM since 1982 at a Gay Men's Health Clinic (Venhälsan) at Stockholm South General Hospital, Sweden.
\end{abstract}

\section{INTRODUCTION}

This article will focus on the unique social, microbiological and medical aspects of sexually transmitted infections (STI) in men who have sex with men (MSM). This is a complex area requiring expert knowledge and frequently a multidisciplinary approach.

Firstly, despite 40 years of gay liberation, the patient may not spontaneously present himself as an MSM to the caregiver. A sexual history should always be taken with great sensitivity, with an open and unprejudiced mind. The patient should be able to speak openly and in some detail about his sexual activities, confident the care provider will be non-judgemental. If good contact is not established and communication between the doctor and patient is insufficient, medically important information might be withheld.

*Address correspondence to this author at the Department of Clinical Science and Education, Karolinska Institute, Södersjukhuset, Unit: Venhälsan, Stockholm, Sweden; Tel: +4686162500; Fax: +4686162509;

E-mail: goran.bratt@sodersjukhuset.se
Secondly, many STIs affecting the mouth or the anal region are prone to be asymptomatic and persistent. Without testing for the right microbes in relevant locations, infections will be missed. To illustrate the high prevalence of STIs in asymptomatic MSM, for example, 7\% of Boston MSM who reported having high risk sex in the preceding 3 months tested positive for at least one STI in the mouth, urethra or anus [1]. It is, however, notable that this study did not test for rectal and oro-pharyngeal Chlamydia trachomatis. Had such tests been included the prevalence might have been significantly higher [1]. Over half of STIs will be missed if only uro-genital testing is performed [2]. In another study of an unselected series of consecutive MSM attending Genito Urinary Medicine (GUM) clinics in the UK for sexual health screening, the prevalence of non-Lymfogranuloma venereum (LGV) Chlamydia trachomatis was 3,3\% in the urethra and $7,0 \%$ in the rectum and the prevalence of LGV was $0,04 \%$ and $0,9 \%$, respectively [3].

Thirdly, many sexual activities engaged in by MSM have implications for the STI panorama they are likely to present with. Unprotected anal intercourse is an especially effective way of transmitting pathogens like Hepatitis B and HIV. 
Another consequence of unprotected anal sex is the increased risk of human papilloma virus (HPV) induced anal cancer among MSM, a risk that is even doubled in individuals co-infected with HIV [4-6]. Oro-anal contacts facilitate the transmission of Hepatitis A, Entamoeba histolytica and other intestinal infections. Furthermore, more advanced sexual practices such as fisting and the use of sex toys seem to be risk factors for blood-blood transmitted pathogens such as Hepatitis $\mathrm{C}$ as well as for rectal-to-rectal STI transmission [3].

Finally, the high and increasing prevalence of longstanding and well-treated HIV infection among MSM contributes to a continuously changing epidemiology, exemplified by the increase in syphilis since 1999 [7-11], the recent reappearance of LGV (variant L2b) [12] and the increase in sexually transmitted Hepatitis C [13].

After the initial, sexually paralysing AIDS shock in the early 1980 's there was a marked decrease of STIs for over 15 years among MSM [14]. However, when the impact of protease-inhibitor based antiretroviral therapy (ART) on survival and general well-being became obvious in 19971998, sexual risk-taking gradually increased among MSM. The emergence of increasingly efficient ART combinations with improving long-term safety and simplicity resulting in an undetectable viral load in the overwhelming majority of treated subjects together with a media-silence regarding HIV have resulted in a "business as usual" attitude to sex. The optimally treated HIV patient's sense of wellbeing and their belief of being less infectious have also had an impact. However, the statement that patients on effective ART who are free of any other STI cannot transmit HIV through sex has been questioned [15]. Other developments facilitating the spread of all STIs include the eroticisation of "barebacking" and the exchange of sperm among many HIV positive MSM, encouraged by numerous internet sites aiming at so called "sero-sorting" and "poz-parties". Obviously, less condom use and an increased number of sexual encounters increase the transmission of other STIs [16].

The aim of this article is to focus on some aspects of asymptomatic as well as symptomatic bacterial and viral STIs of the oral cavity, penis/urethra and rectum, the sexually transmittable viral Hepatitis and HIV in MSM and to discuss testing guidelines. This article is built on a review of published findings, own original data regarding Gonorrhoea and chlamydia and our own experience in treating MSM with all forms of STIs including HIV since 1982 at a Gay Men's Health Clinic (Venhälsan) at Stockholm South General Hospital, Sweden. Venhälsan started in 1982 as a response to the international reports of AIDS and other STIs among MSM with the ambition to reach as many MSM as possible and offer STI-testing and counselling, which since 1985 also included HIV [17]. Venhälsan cares today for 1000 HIV positive patients, of whom $80 \%$ are MSM and have approximately 7000 annual visits for STI/HIV testing.

\section{MATERIALS \& METHODS}

All patients presenting at Venhälsan are offered oropharyngeal, urethral/urin and anorectal testing for Gonorrhoea and chlamydia. We have revised all the files of patients with positive Gonorrhoea and chlamydia results during 2007 and 2008. All patients are MSM.

In addition a review of the literature on STIs in MSM has been performed and our results are discussed in relation to American and European published reports.

\section{Results from Venhälsan}

Two hundred and thirty six individuals tested positive for Gonorrhoea, $17 \%$ had a known HIV-infection and in 5\% HIV was diagnosed at the time of Gonorrhoea (Table 1a). The median age was 31 years. Symptoms were noted only in $32 \%, 13 \%$ and $96 \%$ of the patients with ano-rectal, oropharyngeal and urethral Gonorrhoea, respectively (Table 1b). Signs/symptoms of proctitis were not more common in HIV-positive as compared to HIV-negative MSM (Table 1c). Newly diagnosed HIV-infection occurred in $8 \%$ and $3 \%$ of the patients with ano-rectal and urethral Gonorrhoea, respectively, but not in any of the patients with oropharyngeal Gonorrhoea (Table 1b). Only 4\% and 15\% of patients with ano-rectal Gonorrhoea with and without signs/symptoms of proctitis, respectively, were positive in the urethral Gonorrhoea culture (Table 1c).

Four hundred and thirty one tested positive for chlamydia, 24\% had a known HIV-infection and in 4\% HIV was diagnosed at the time of chlamydia (Table 2a). The median age was 34 years. Symptoms were noted only in $34 \%, 16 \%$ and $51 \%$ of the patients with ano-rectal, oropharyngeal and urine chlamydia, respectively (Table $\mathbf{2 b}$ ). Of the patients with rectal chlamydia 17(6\%) had anal condylomata. Signs/symptoms of proctitis were more common in HIV-positive as compared to HIV-negative MSM (43/74 (58\%) vs 51/199 (26\%); p $<0,001$ (Fisher's exact test)). Of HIV-positive and HIV-negative patients with signs/symptoms of proctitis and positive Chlamydia test $30 \%$ and $4 \%$, respectively had LGV (Table $2 \mathrm{c}$ ). Newly diagnosed HIV-infection occurred in $5 \%, 2 \%$ and $2 \%$ of the patients with ano-rectal, oro-pharyngeal and urine chlamydia, respectively (Table $2 \mathbf{b}$ ). Only $6 \%$ and $14 \%$ of patients with ano-rectal chlamydia with and without signs/symptoms of proctitis, respectively, were positive for chlamydia in the urine (Table 2c). Contact tracing was the most common reason for the visit in patients with oro-pharyngeal and anorectal Gonorrhoea and chlamydia (Tables 1b, 1c, $2 \mathbf{b}$ and $\mathbf{2 c}$ ).

\section{Localized Asymptomatic STIs}

Gonorrhoea has been shown to be transmitted bidirectionally through oro-penile sex [18] and the same seems true for chlamydia [19]. Gonorrhoea and chlamydia usually cause no symptoms in the oral cavity and oro-pharyngeal symptoms are not predictive of Gonorrhoea/chlamydia, making this site an ideal and frequently overlooked STI reservoir. In one study only $18,2 \%$ and $16,7 \%$ of the cases with oro-pharyngeal Gonorrhoea and chlamydia, respectively, would have been identified on symptom-lead testing [20]. We found $87 \%$ and $84 \%$ of MSM with oropharyngeal Gonorrhoea and chlamydia, respectively, to be asymptomatic and $51 \%$ and $43 \%$ of the patients with positive oro-pharyngeal tests, respectively, were only positive in the mouth (Tables $\mathbf{1 b}$ and $\mathbf{2 b}$ ). Syphilitic ulcers are probably also often overlooked in the oral and ano-rectal sites, especially as they can be painless. In our practice only $9 \%$ of 
primary syphilitic lesions are located orally and $23 \%$ anorectally [21]. Overall ano-rectal symptoms do not differ between men with and without ano-rectal gonorrhoea/nonLGV chlamydia [22]. However, heavy anal discharge and pain was associated to ano-rectal Gonorrhoea in one study [22]. Patients with ano-rectal Gonorrhoea/non-LGV chlamydia are more likely to be asymptomatic than those with urethral infections [20, 23, 24]. Rectal Gonorrhoea is reported to be asymptomatic in $50-68 \%$ and rectal non-LGV chlamydia in $52-86 \%$ [3, 7, 19, 24-26], Tables $\mathbf{1 b}$ and $\mathbf{2 b}$. We found $55 \%$ of MSM with rectal Gonorrhoea to have normal anoscopy (Table 1b). Most oro-pharyngeal and anorectal Gonorrhoea and chlamydia would go undiagnosed and untreated without testing in these sites [2, 26, 27], for example we found that $67 \%$ and $82 \%$, respectively, of the patients with positive ano-rectal samples were positive only in this site (Tabled $\mathbf{1 b}$ and $\mathbf{2 b}$ ). Routine testing for oropharyngeal and asymptomatic ano-rectal STI:s in MSM in different settings has revealed a Gonorrhoea prevalence of $1,7-9,2 \%$ and $5,0-6,9 \%$, respectively, and a chlamydia prevalence of $1,2-1,7 \%$ and $4,7-8,0 \%$, respectively $[1,7,18$ $20,28,29]$. Urethral chlamydia, now common in MSM with a prevalence of $6 \%$ in the US [30], is asymptomatic in $42-$ $50 \%$ of the cases [3] (Table 2b). A positive urine/urethral chlamydia test is found in only $8-15 \%$ of MSM with asymptomatic rectal chlamydia [26] (Table 2c).

We found an overrepresentation of oro-pharyngeal chlamydia and coexisting oro-pharyngeal and rectal chlamydia among MSM being contact traced/partner notified for chlamydia, high lightening the importance of asymptomatic oral and rectal chlamydia reservoirs [19]. Rectal Gonorrhoea and chlamydia often co-exist, 6,5-13,4\% of patients with rectal chlamydia also had Gonorrhoea [19, 26] (Table 2b), while $17,8 \%$ of patients with rectal Gonorrhoea also had chlamydia (Table 1b).

Although LGV often presents with severe proctitis, asymptomatic ano-rectal LGV does occur, the reported frequency varies considerably from $0 \%$ in Canada, $5-17 \%$ in London and $12-13 \%$ in Stockholm to the majority of cases in the Netherlands [3, 19, 26, 28, 31, 32] (Table 2c).

\section{Localized Symptomatic STIs}

\section{Oro-Pharyngeal}

Of patients with oro-pharyngeal Gonorrhoea and chlamydia, $10-13 \%$ and $16 \%$ reported pharyngitis and/or tonsillitis [33] (Tables $\mathbf{1 b}$ and $\mathbf{2 b}$ ). Oro-pharyngeal Gonorrhoea is more difficult to eradicate than ano-genital with approximately $9-10 \%$ treatment failures on single dose cefixime or ceftriaxone - a further contributing factor to a reservoir for continuing transmission $[27,34]$. Treatment with single dose cefixime in combination with $1 \mathrm{~g}$ azithromycin has improved efficacy and been reported, in some studies with small numbers of patients, to result in $100 \%$ negative control cultures [34].

Cervical lymphadenopathy related to oro-pharyngeal LGV has been reported and might become an increasing problem [35].

\section{Penile}

Urethral Gonorrhoea is usually symptomatic and is rare in asymptomatic men $[1,20]$ (Table 1b). Symptoms of gonococcal urethritis include various degrees of urinal pain/itching and mucopurulent discharge. Urethral chlamydia, in contrast, only causes symptoms in $32-69 \%$ [3, 19, 26] (Table 2b). The symptoms of chlamydia infection are usually mild with a watery discharge. Chlamydial/gonococcal epididymitis or prostatitis are rarely seen in our patient cohort, possibly because such patients are acutely ill and tend to seek the emergency ward rather than an STI clinic. LGV may cause genital ulcers and urethral infection with inguinal adenopathy and should always, together with Herpes simplex and primary syphilis, be a differential diagnosis when evaluating genital ulcers [36]. Oral sex may lead to oro-penile transmission of various respiratory pathogens such as Moraxella, Streptococci spp and Haemophilis parainfluenzae [37,38] and unprotected anal sex might cause E. coli urethritis. Although not extensively studied, urethritis caused by Mycoplasma genitalium, does not seem to be overrepresented in MSM, probably since it is not transmitted by oral sex [39].

\section{Ano-Rectal}

Symptoms of proctitis are: pain, purulent and/or haemorrhagic discharge, tenesmus, irritation, itching, diarrhoea and/or constipation [40]. It is not uncommon that patients with a severe sexually acquired rectal infection like LGV have symptoms suggestive of Crohn's disease [41]. They may initially present at a gastroenterology or colorectal department and receive treatment for inflammatory bowel disease [42, 43] (Table 1b). Even in the pre-AIDS 1970's the frequency of ano-rectal disease in MSM received attention and was given the misleading term "gay Bowel Syndrome" [44]. This represented a mixture of intestinal infections like amoebiasis, shigellosis, proctologic problems like peri-rectal abscesses, fissures, haemorrhoids, fistulas, rectal trauma, itching and dyspareunia and STIs. Infectious proctitis is more common than non-infectious with common causes including Gonorrhoea, chlamydia, syphilis and Herpes simplex [40]. In a series of 125 MSM with symptomatic proctitis in the Netherlands $26 \%$ had LGV, $18 \%$ Gonorrhoea and $24 \%$ non-LGV chlamydia [31]. For details about clinical features, diagnostic tests and management of proctitis the reader is referred to the 2007 updated European Guidelines (IUSTI/WHO) on the management of proctitis, proctocolites and enteritis caused by sexually transmitted pathogens [45]. It is recommended to start treatment at least covering Gonorrhoea, LGV and Herpes in severe cases [40].

\section{Ano-Rectal Herpes Simplex}

Acute Herpes simplex proctitis may cause fever, and in addition to the symptoms described above difficulty in urinating, sacral paresthesia, inguinal lymphadenopathy, severe ano-rectal pain, and peri- and intra-anal ulcerations, especially during the first episode of HSV-2. HSV-2 was detected in $23 \%$ of MSM with proctitis in one early study [46].

\section{Ano-Rectal Mycoplasma Genitalium}

There are only a few studies of ano-rectal Mycoplasma genitalium, but $5,4 \%$ of rectal specimens in a cross-sectional pilot study in an STI clinic in San Fransisco were positive and there was a weak association to rectal symptoms and proctitis [47]. Interestingly, in the multivariate analysis only 
positive HIV status was associated with Mycoplasma genitalium infection [47].

\section{Ano-Rectal Syphilis}

It is important to remember that syphilis may cause severe very painful ulcerative proctitis, sometimes with an anorectal mass.

\section{Ano-Rectal Gonorrhoea}

Symptoms of proctitis were significantly more common in rectal Gonorrhoea than in isolated rectal non-LGV chlamydia infection in one study [48]. In our cohort of 100 patients with rectal Gonorrhoea, 32\% presented with anorectal symptoms and $45 \%$ had an anoscopy verified proctitis (Table 1b). Two patients had anal abscesses with growth of gonococci and one patient had been treated for inflammatory proctitis at the gastroenterology department prior the correct diagnosis being made (Table 1b).

\section{$\underline{\text { Ano-Rectal Non-LGV Chlamydia and LGV }}$}

Both non-LGV chlamydia and LGV can cause severe proctitis, however, non-LGV infections are usually milder $[41,43]$. As early as 1981-83 LGV was associated with severe proctitis [41], one case presenting with massive rectal bleeding [42]. Although urethral/penile LGV presenting with ulcers has been reported, severe painful ulcerative purulent proctitis with rectal discharge, urge to defecate, tenesmus and the passage of blood are frequently the dominating symptoms of LGV [49]. Untreated chronic LGV may lead to abscesses that may rupture, severe perianal fistulas, genital elephantiasis, strictures and fibroses and may resemble Crohn's disease, although the appearance is non-specific [49]. The local lymph nodes are involved with pain, swelling, necrosis and perforation $[12,49]$. Since the recognition of the ongoing outbreak of LGV among MSM in Rotterdam, Holland [50], infections have been reported from many parts of Europe, North America and Australia [12, 31, 49] and LGV has become endemic among MSM in some areas of the UK [3]. From our experiences 14-16\% of patients with symptomatic rectal chlamydia had LGV, a figure increasing to $30 \%$ in the case of HIV-positive patients [19] (Table 2c). The majority of LGV patients in the current outbreak are HIV positive, and often have other STIs at the LGV diagnosis [12,19]. A high proportion of HIV negative MSM with LGV become HIV positive soon after the LGV diagnosis [51]. In a Dutch study comparing proctitis of different causes, LGV patients were older, had more often a history of syphilis and Hepatitis $\mathrm{C}$ and $78 \%$ were HIVpositive [31]. The use of sex toys, enemas, having sex at sex parties and sex with HIV positive partners came out as significant LGV risk factors in multiple logistic regression [31]. In a case-control study of symptomatic rectal infections

Table 1a. All Gonorrhoea Diagnosed at Venhälsan, Stockholm 2007-2008. Data are Given as n and (\%)

\begin{tabular}{|c|c|c|c|c|c|}
\hline $\mathbf{n}$ & $\begin{array}{c}\text { Positive at More } \\
\text { Than One Site } \\
\mathbf{n}(\%)\end{array}$ & (Years: Median and Range) & $\begin{array}{c}\text { Also Diagnosed with } \\
\text { Chlamydia } \\
\text { n (\%) }\end{array}$ & $\begin{array}{c}\text { Known HIV } \\
\text { Infection } \\
\text { n (\%) }\end{array}$ & $\begin{array}{c}\text { Newly Diagnosed HIV } \\
\text { Infection } \\
\text { n (\%) }\end{array}$ \\
\hline \hline 236 & $47(20)$ & $31(17-67)$ & $42(18)$ & $39(17)$ & $11(5)$ \\
\hline
\end{tabular}

Table 1b. Gonorrhoea in Different Sites Diagnosed at Venhälsan, Stockholm 2007-2008. Data are Given as $\mathbf{n}$ and (\%)

\begin{tabular}{|c|c|c|c|c|c|c|}
\hline $\begin{array}{c}\text { Site of Positive } \\
\text { Gonorrhoea } \\
\text { Culture }\end{array}$ & $\mathbf{n}$ & $\begin{array}{c}\text { Only One Site } \\
\mathbf{n}(\%)\end{array}$ & $\begin{array}{c}\text { Testing Due to } \\
\text { Contact Tracing } \\
\mathbf{n}(\%)\end{array}$ & $\begin{array}{c}\text { Symptoms in the } \\
\text { Positive Site } \\
\mathbf{n}(\%)\end{array}$ & $\begin{array}{c}\text { Known HIV } \\
\text { Infection } \\
\mathbf{n}(\%)\end{array}$ & $\begin{array}{c}\text { Newly Diagnosed } \\
\text { HIV Infection } \\
\mathbf{n}(\%)\end{array}$ \\
\hline \hline Pharyngeal & 87 & $44(51)$ & $29(33)$ & $11(13)$ & $6(7)$ & $0(0)$ \\
\hline Urethral & 103 & $79(77)$ & $5(5)$ & $99(96)$ & $20(20)$ & $3(3)$ \\
\hline Anorectal & 100 & $67(67)$ & $43(43)$ & $32(32)^{*}$ & $19(19)$ & $8(8)$ \\
\hline
\end{tabular}

${ }^{*} 45$ (45\%) had pathological anoscopy. Two patients had rectal abscesses with growth of gonococci, two had rectal fissures and one was admitted to the gastroenterology clinic and received treatment for inflammatory bowel disease.

Table 1c. Ano-Rectal Gonorrhoea at Venhälsan, Stockholm 2007-2008. Data are Given as n and (\%)

\begin{tabular}{|c|c|c|c|c|c|c|}
\hline $\begin{array}{c}\text { Positive Ano-Rectal } \\
\text { Gonorrhoea (n=100) }\end{array}$ & $\mathbf{n}(\mathbf{\%})$ & $\begin{array}{c}\text { Also Positive in } \\
\text { Urethra } \\
\mathbf{n}(\mathbf{\%})\end{array}$ & $\begin{array}{c}\text { Testing Due to } \\
\text { Contact Tracing } \\
\mathbf{n}(\%)\end{array}$ & $\begin{array}{c}\text { Ano-Rectal } \\
\text { Chlamydia } \\
\mathbf{n}(\%)\end{array}$ & $\begin{array}{c}\text { Known HIV } \\
\text { Infection } \\
\mathbf{n}(\%)\end{array}$ & $\begin{array}{c}\text { Newly Diagnosed } \\
\text { HIV Infection } \\
\mathbf{n}(\%)\end{array}$ \\
\hline \hline $\begin{array}{c}\text { Sign/symptom of proctitis; } \\
\text { HIV-positive and negative }\end{array}$ & $45(45)$ & $2(4)$ & $9(20)$ & $9(20)$ & $9(20)$ \\
\hline $\begin{array}{c}\text { Sign/symptom of proctitis; } \\
\text { HIV-positive }\end{array}$ & $13(13)$ & $0(0)$ & $2(15)$ & $4(31)$ & $9(69)$ & $4(31)$ \\
\hline $\begin{array}{c}\text { Sign/symptom of proctitis; } \\
\text { HIV-negative }\end{array}$ & $32(32)$ & $2(6)$ & $7(22)$ & $5(16)$ & 0 & 0 \\
\hline $\begin{array}{c}\text { No sign/symptom of proctitis; } \\
\text { HIV-positive and negative }\end{array}$ & $55(55)$ & $8(15)$ & $34(62)$ & $10(18)$ & $10(18)$ & $4(7)$ \\
\hline
\end{tabular}


Table 2a. All Chlamydia Diagnosed at Venhälsan, Stockholm 2007-2008. Data are Given as n and (\%).

\begin{tabular}{|c|c|c|c|c|c|}
\hline $\mathbf{n}$ & $\begin{array}{c}\text { Positive at More } \\
\text { than One Site } \\
\mathbf{n}(\%)\end{array}$ & $\begin{array}{c}\text { Age } \\
\text { (Years; Median; Range) }\end{array}$ & $\begin{array}{c}\text { Also Diagnosed with } \\
\text { Gonorrhoea } \\
\text { n (\%) }\end{array}$ & $\begin{array}{c}\text { Known HIV } \\
\text { Infection } \\
\text { n (\%) }\end{array}$ & $\begin{array}{c}\text { Newly Diagnosed } \\
\text { HIV Infection } \\
\text { n (\%) }\end{array}$ \\
\hline \hline 431 & $50(12)$ & $34(19-74)$ & $45(10)$ & $103(24)$ & $16(4)$ \\
\hline
\end{tabular}

Table 2b. Chlamydia in Different Sites Diagnosed at Venhälsan, Stockholm 2007-2008. Data are Given as n and (\%)

\begin{tabular}{|c|c|c|c|c|c|c|}
\hline $\begin{array}{c}\text { Site of Positive } \\
\text { Chlamydia }\end{array}$ & $\mathbf{n}$ & $\begin{array}{c}\text { Only One Site } \\
\mathbf{n}(\%)\end{array}$ & $\begin{array}{c}\text { Testing Due to } \\
\text { Contact Tracing } \\
\mathbf{n}(\%)\end{array}$ & $\begin{array}{c}\text { Symptoms in the } \\
\text { Positive Site } \\
\mathbf{n}(\%)\end{array}$ & $\begin{array}{c}\text { Known HIV } \\
\text { Infection } \\
\mathbf{n}(\%)\end{array}$ & $\begin{array}{c}\text { Newly Diagnosed } \\
\text { HIV Infection } \\
\mathbf{n}(\%)\end{array}$ \\
\hline \hline Pharyngeal & 49 & $21(43)$ & $24(49)$ & $8(16)$ & $6(12)$ & $1(2)$ \\
\hline Urethral & 168 & $138(82)$ & $44(26)$ & $85(51)$ & $26(15)$ & $3(2)$ \\
\hline Anorectal & 273 & $224(82)$ & $86(32)$ & $94(34)$ & $60(22)$ & $14(5)$ \\
\hline
\end{tabular}

Table 2c. All Ano-Rectal Chlamydia at Venhälsan, Stockholm 2007-2008. Data are Given as n and (\%); GC: Gonorrhoea

\begin{tabular}{|c|c|c|c|c|c|c|c|}
\hline $\begin{array}{c}\text { Positive Ano-Rectal } \\
\text { Chlamydia (n=273) }\end{array}$ & $\mathbf{n}(\mathbf{\%})$ & $\begin{array}{c}\text { Also Positive in } \\
\text { Urine/Urethra } \\
\mathbf{n}(\%)\end{array}$ & $\begin{array}{c}\text { Testing Due to } \\
\text { Contact Tracing } \\
\mathbf{n}(\%)\end{array}$ & $\begin{array}{c}\text { LGV } \\
\mathbf{n}(\%)\end{array}$ & $\begin{array}{c}\text { Ano-Rectal } \\
\text { GC } \\
\mathbf{n}(\%)\end{array}$ & $\begin{array}{c}\text { Known HIV } \\
\text { Infection } \\
\mathbf{n}(\%)\end{array}$ & $\begin{array}{c}\text { Newly Diagnosed } \\
\text { HIV Infection } \\
\mathbf{n}(\%)\end{array}$ \\
\hline \hline $\begin{array}{c}\text { Sign/symptom of proctitis; } \\
\text { HIV-positive and negative }\end{array}$ & $94(34)$ & $6(6)$ & $24(26)$ & $15(16)$ & $10(11)$ & $38(40)$ & $5(5)$ \\
\hline $\begin{array}{c}\text { Sign/symptom of proctitis; } \\
\text { HIV-positive }\end{array}$ & $43(58)$ & $2(5)$ & $7(16)$ & $13(30)$ & $5(12)$ & $38(88)$ & $5(12)$ \\
\hline $\begin{array}{c}\text { Sign/symptom of proctitis; } \\
\text { HIV-negative }\end{array}$ & $51(26)$ & $4(8)$ & $17(33)$ & $2(4)$ & $5(10)$ & 0 & 0 \\
\hline $\begin{array}{c}\text { No sign/symptom of proctitis; } \\
\text { HIV-positive and negative }\end{array}$ & $179(66)$ & $25(14)$ & $62(35)$ & $2(1)$ & $12(7)$ & $22(12)$ & $9(5)$ \\
\hline
\end{tabular}

in London LGV was associated with rectal discharge, higher age, fisting, HIV infection and less protected anal intercourse [43]. LGV treatment consists of doxycycline $100 \mathrm{mg}$ twice daily for 21 days and should be initiated on suspicion in chlamydia positive proctitis, especially in HIV-positive patients, since confirmation might be delayed [40, 43].

\section{Syphilis}

Untreated syphilis is highly contagious during the first 2 years (early syphilis). The main route of transmission is unprotected oral and anal intercourse. Since unprotected oral sex, considered less risky regarding HIV transmission, is widely practised among both HIV negative and positive MSM, it has been considered the most important manner of transmission [9, 52]. High numbers of anonymous contacts and delays in diagnosis lead to an increased transmission rate and great difficulties in contact tracing [9]. During the 1980's and early 90's there was a marked decrease of syphilis in Western Europe [53, 54]. Experience of syphilis infection both among doctors and MSM was lacking at the beginning of the current outbreaks. All genital ulcers, nonitching exanthema and severe disease symptoms (e.g. fever, fatigue, lymphadenopathy, hepato-splenomegaly, increased liver enzymes, neurological and ophtalmological symptoms) without an obvious explanation should lead to testing for syphilis, especially in MSM, regardless of HIV status.
During the last 10 years there have been numerous outbreaks of syphilis among MSM [7], starting in Dublin, Oslo and cities in the UK, to be followed in all major cities in Europe and North America, as well as other parts of the world [7, 9, $10,55,56]$. There is a strong association between syphilis and other STIs, especially HIV [7-11]. The HIV prevalence among MSM diagnosed with syphilis in Europe is reported between $14-59 \%$ [7, 21]. HIV infection seems to increase the susceptibility for syphilis and co-infection with syphilis was the greatest risk factor for a new HIV infection in one study [57]. Between 2-5\% are diagnosed with syphilis and HIV at the same time $[7,21]$. We have found that $10 \%$ of HIV negative men with syphilis 1999-2009 have become HIV infected after their syphilis infection and that $25 \%$ of newly diagnosed HIV positive men have had syphilis [21]. Untreated syphilis in HIV positive subjects leads to increased viral load and decreased CD4 levels [58] and is reported to progress more rapidly with increased risk for early cerebral/ocular involvement, especially if the CD4 count is low and the HIV infection is untreated [59]. There is an increased risk to infect sex partners with $\operatorname{HIV}[11,58,60]$. In $10-13 \%$ of patients gonorrhoea and/or chlamydia is also diagnosed at the same time as syphilis $[9,21]$ and of our patients with Gonorrhoea and chlamydia 4 and $3 \%$, respectively, were simultaneously diagnosed with syphilis (data not shown). Staging of the syphilis infection in our cohort showed $52 \%$ to have primary syphilis, usually with a 
penile primary lesion (68\%), 22\% to have secondary syphilis while $26 \%$ were in latency [21]. The median age at syphilis diagnosis is higher than for gonorrhoea/chlamydia and similar to the median age at HIV-diagnosis in Sweden [21]. Relapses/re-infections by syphilis are common [9, 21], especially in HIV positive individuals [59]. Non-treponemal antigen tests like the rapid regain test (RPR) and the venereal disease research laboratory (VDRL) test are used to rapidly detect symptomatic syphilis, and should always be confirmed by a treponemal antigen test like TPPA [61]. Screening serology (eg VDRL, TPPA) can be negative up to one month after the presentation of a chancre and up to three months after being infected [61]. Specific tests, e. g. tests based on IgM-antibodies or PCR can become positive earlier, but are expensive and rarely included in routine clinical strategies. In clinical practice treatment "on clinical suspicion" is often preferred to the "wait for seroconversion" strategy in sero-negative patients with a history indicative of syphilis.

Neurosyphilis is diagnosed by liquor analysis. HIV coinfection and a high VDRL or RPR titre should raise the suspicion of neurosyphilis [61, 62]. Treatment should be handled by experienced clinics, usually at dermatovenereological or infectious disease units and follow international guidelines [61]. Syphilis treatment is the same regardless of HIV status.

\section{Hepatitis A}

Hepatits A (HAV) is easily transmitted through sexual practices involving fecal-oral exposure [63]. Although HAV never becomes chronic, HAV more often causes significant clinical disease than hepatitis B. There have been several outbreaks of HAV in MSM e.g. in 1979-1980 in Stockholm [64]. In 1982, prior to any HAV vaccination, we found $26 \%$ of the attending MSM to be anti-HAV positive [17]. Although effective vaccination with formalin killed HAV (preferably administered as two doses with 6 months interval) has been generally available at a low cost for many years, only half of MSM in UK are anti-HAV IgG positive [65]. The relative failure in offering MSM HAV-vaccination has resulted in continuing regular HAV outbreaks, e.g. in Copenhagen 2004 where casual sauna sex appeared to be a risk factor [66]. As the general immunity to HAV decreases in the western community, all MSM not living in monogamous relationships, are advised to undergo HAV immunization [63].

\section{Hepatitis B}

In industrialized countries most cases of hepatitis B virus (HBV) infection are acquired through sexual intercourse or through needle sharing by intravenous drug users (IVDU) [63]. The major risk factors for HBV infection in MSM include receptive anal intercourse and the number of sex partners [67]. The initial epidemiological matching of HBV and AIDS generated a hypothesis of HBV being a cofactor for AIDS [68]. HBV infection is prevalent and most often asymptomatic among MSM but may lead to significant morbidity and death. The prevalence of positive HBV surface antigen (HBsAg) and antibodies to the HBV core antigen (anti-HBc) has been found to be 1-6\% and 12-68\%, respectively, in MSM in various materials during the last 30 years $[17,48,63,69]$. During the last two decades the proportion of newly HIV diagnosed MSM at our clinic with positive $\mathrm{HBsAg}$ and positive anti-HBc has been $3 \%$ and $38 \%$, respectively (own unpublished data). Chronic HBV infection is related to $60-90 \%$ of all hepatocellular carcinomas in adults, a preventable disease as first evidenced by the universal vaccination program in Taiwan [70]. Although an effective recombinant vaccine has been in existence for 25 years, vaccination rates among MSM are still low [71], although rising [48]. Routine HBV immunization with 3 injections, which in most countries has been introduced as universal childhood vaccination, is also recommended for all MSM and for persons evaluated or treated for STIs [63]. Modern antiviral therapy in individuals who develop chronic infection and do not clear the virus themselves include tenofovir, which is highly effective in promoting a durable and sustained suppression of the virus, increasing survival and quality of life and hopefully preventing end stage liver disease and hepatocellular cancer. Such treatment aims at undetectable HBV DNA and is comparable to HIV-treatment [72].

\section{Hepatits C}

Although needle sharing among IVDU is considered the main way of transmission, a proportion of $\mathrm{HCV}$ infected individuals are not IVDU, many of whom may have been sexually infected. HCV infection causes no symptoms during the first couple of decades; the only signs being raised liver enzymes. Since 2000 there has been a marked rise in hepatitis $\mathrm{C}(\mathrm{HCV})$ infection in HIV-positive MSM in different countries with circulating clusters of limited genotypes (1a, 4d, 3a, $1 \mathrm{~b}$ and $2 \mathrm{~b} / \mathrm{c})$, suggesting an "international transmission network" [73]. Sexual spread of HCV seems to coincide with syphilis and LGV in HIV positive MSM [74]. In France, for example, the prevalence of $\mathrm{HCV}$ among HIV-positive MSM was 3,1\% in 2004 [75] and in the UK an annual incidence rise of $20 \%$ among HIV positive MSM was found between 2002 and 2006 [76], whilst the prevalence in HIV-positive MSM in Amsterdam increased from $15 \%$ to $21 \%$ between 2007 and 2008 [13]. It is important to be aware of the persistent high-risk behaviour in a subgroup of HIV positive MSM and perform intense counselling as well as screening for STIs including HCV in this group. Finding all HCV infected individuals is crucial, since today's and tomorrow's treatment options are rapidly making HCV a potentially curable disease [77]. We have neither ourselves nor in the literature found an overrepresentation of HCV in HIV negative MSM. Although this could change rapidly, for the moment there are no data indicating spread of HCV to HIV negative MSM through sex [76].

\section{Human Papilloma Virus (HPV)}

HPV is easily transmittable through all intimate contacts. International studies show a high prevalence of HPV in MSM in general and in HIV positive MSM in particular. The basal cell of the anal epithelium is highly susceptible to HPV infection. Approximately 15 types of HPV are classified as "high risk" (e.g. HPV 16 and 18) due to their association with cervical cancer, other ano-genital cancers, and tonsillar squamous cell carcinoma $[78,79]$. In addition, there are also a number of "low risk" HPV types e.g. HPV 6 and 11 related to condylomata acuminata (genital warts). Despite the high 
prevalence of persistent HPV infection, the progression to pre-cancerous dysplasia tends to be relatively rare and slow, thus allowing for intervention over long time [78]. In a sample of MSM $85 \%$ had "low-risk" and 77\% "high-risk" anal HPV, with a mean of 4.2 concurrent HPV types in HIV negative and 7.1 in HIV positive men. "High-risk" HPVs were associated with anal condyloma in HIV negative and anal bleeding in HIV positive men [80]. In another sample from San Francisco, 34\% of the HIV negative MSM and $72 \%$ of the HIV positive MSM carried "high-risk" HPV [81]. Furthermore, a longitudinal Canadian study found anal HPV in almost $98 \%$ of HIV-positive MSM, with a mean of five types simultaneously, most frequently HPV 16 (38\%) and HPV $6(35 \%)$ with the lowest clearance rate seen for HPV 16 [82].

\section{Anal Cancer}

Cervical and anal cancers are similar in so far as they occur in the transition zone between columnar and squamous epithelium. There is increasing evidence that high-grade HPV-related anal lesions can progress to cancer over time [83]. A recent review comprising 37 international studies found an HPV 16/18 prevalence of $72 \%$ in invasive anal cancer, $69 \%$ in high-grade and $27 \%$ in low-grade anal squamous intraepithelial lesions [84]. Cross-sectional studies have found prevalence's of anal cancer precursor changes of $5-35 \%$ in HIV negative and $15-59 \%$ in HIV positive MSM $[81,85,86]$. A French study found HPV related lesions in $37 \%$ of HIV infected MSM, of which over half hade histologically verified dysplasia [87]. Risk factors for squamous intraepithelial lesions in HIV negative and anal cancer in HIV positive MSM include older age at first receptive anal intercourse, high frequency of unprotected receptive anal intercourse, use of injection drugs, anal HPV infection and higher number of concurrent HPV types [85, 87]. Other contributing factors include low CD4 cell count, and cigarette smoking $[83,88]$. The incidence of anal cancer is increasing and is particularly high in MSM with the highest incidence in HIV infected MSM [78]. The relative risk for anal cancer in HPV infected individuals as compared to the general population is 31.2 in MSM and up to 60 in HIV positive MSM and actually both are higher than for cervical cancer [4-6]. HIV infected patients are at higher risk of viral persistence, multiple HPV genotypes (mainly HPV16), squamous intraepithelial cancer precursor lesions and progress to invasive cancers [89]. The longer survival of HIV-positive subjects allows progression of HPV preneoplastic disease to cancer, whereas immunologic improvement does not affect the incidence of HPVinfections, which is more related to risk behaviour. Anal cancer is one of the most common non-AIDS defining tumours in HIV positive MSM and is increasing despite effective ART [83]. In our own clinical cohort of 202 HIV infected patients, of whom 188 are MSM who started ART in 1996, eight (4\%) have developed anal cancer to date (Bratt, Eriksson et al. unpublished data).

\section{HPV-Vaccines}

In 2006, new vaccines against HPV 16 and 18 with or without effect also against two "low-risk" HPVs were licensed in the US and Europe. The vaccine's preventive effect can only be fully achieved if given prior to HPV exposure and if followed up with booster doses. Recently, vaccination programs for girls have been implemented in several European countries. However, the models that underlie the implementation of those vaccination programs do not take into account non-cervical HPV related cancers and do not consider other sexual behaviour than conventional heterosexual intercourse [90]. A review and a meta-analysis suggest that HPV vaccination could prevent $80 \%$ of anal carcinoma if both sexes were included in vaccination programs $[84,91]$. Although sparsely investi-gated among MSM, studies indicate lack of knowledge about HPV and its relation to condyloma and anal cancer in general [92, 93] and about HPV vaccines in particular [94]. We feel that there is an urgent need to investigate the cancer preventive effect of HPV vaccines in MSM and the feasibility of including both men and women in vaccine programs.

\section{HIV}

STIs are markers for high risk sex through which HIV can be transmitted. STIs also facilitate transmission and acquisition of HIV through several direct biological mechanisms, including boosting genital HIV shedding, increasing recruitment of "ready to be infected" lymphocytes and macrophages and disrupting the mucosal barrier [57, 60]. Gonorrhoea, syphilis and to a lesser extent chlamydia are associated with higher amounts of HIV in genital secretions in co-infected subjects [95]. To increase the knowledge about actual risk factors for becoming HIV positive detailed studies of the recently HIV infected MSM are crucial. Recently acquired HIV is associated with having had an STI the last years and often having a concurrent STI, especially syphilis and rectal and urethral Gonorrhoea [9698]. In one study $23 \%$ of newly HIV diagnosed MSM were concomitantly co-infected with another STI, with syphilis as the greatest risk $(\mathrm{OR}=11,1(95 \% \mathrm{CI}: 7,7-15,8))$ [57]. In our own clinic this figure is $29 \%$, while $41 \%$ had had an STI during the last 2 years [99]. Gonorrhoea and chlamydia were found in $26 \%$ and $19 \%$, respectively, among newly HIVdiagnosed MSM in San Francisco [100]. Concurrent chlamydia, Gonorrhoea and syphilis were significant predictors of new HIV in four US metropolitan areas 20022006 [101]. Ano-rectal Gonorrhoea is an independent risk factor for HIV seroconversion [102] and high rates of new HIV infections have been observed after ano-rectal Gonorrhoea [98]. Also chlamydia has been associated to HIV infection [103]. HIV positive MSM have a greater STI burden, especially urethral Gonorrhoea and syphilis and are more often asymptomatic as compared to HIV negative MSM. A Californian study found a baseline prevalence of STIs of $14 \%$ and an annual incidence of 21 cases per 100 person years in asymptomatic HIV positive MSM [104].

\section{DISCUSSION}

Prompt testing, counselling, diagnosing and treatment of STIs are extremely important in a comprehensive HIV prevention strategy among MSM [60]. A visit at an STI clinic is also an excellent opportunity for the nurse or physician to discuss safer sex practices and to update the client of the current local STI situation and the importance of STIs, especially rectal infections and syphilis for HIV transmission [21,98].

HIV testing/counselling (traditional or rapid test) should always be suggested since it is crucial that HIV infected 
individuals become aware of their infection as soon as possible after being infected. We have had excellent experience with a low-threshold rapid HIV testing program combined with a single structured counselling session. STIs are important cofactors for HIV transmission and markers of unprotected sex. A sexual history obtained in the clinical setting is often unreliable, and a standard testing procedure has many advantages over symptom-driven testing [104]. This is regardless of whether the patient seeks for localized symptoms or a general check-up. Since co-infections are common, a standardized testing regime including all infections at all locations is necessary. It is crucial to encourage all nurses and physicians engaged in the health care of MSM to follow guidelines for STI screening [104]. Gonorrhoea and chlamydia testing (with the methods as recommended by the local lab) should be carried out from the oral cavity (tonsillar and pharyngeal, respectively), the urethra/urine and the anal canal. Since lubricants have a mild bacteriostatic effect, it is important to use a technique minimising lubrication prior to testing, either blindly or under direct vision through the anoscope [40]. Rectal examination with anal inspection and digital palpation is an excellent and simple method to detect warts, ulcers and tumours. Positive rectal chlamydia samples should be sent to a specialist lab for LGV sequencing. Blood should be tested for syphilis, Hepatitis A, B (in non-immune subjects) and C and HIV. Patients that are contact traced and/or partner notified for one infection should always be tested also for the other infections since different STIs very often co-occur in this group. Hepatitis A and B vaccination should always be suggested in non-immune subjects. Annual routine STI screening including HIV testing is recommended for all sexually active MSM [105]. Screening every 3-6 months has been advised for those at highest risk i.e. men with multiple partners, those using alcohol and drugs in conjunction with sex and those travelling to high risk cities for sex encounters. Sexually active HIV-positive MSM should have an STI screening including rectal palpation and anoscopy at least annually. We think that there is a strong need for specialist departments aimed at MSM where patients can feel secure, with a team that is up to date on the continuously changing STI epidemic situation. In such an environment important data can be collected and research stimulated.

\section{REFERENCES}

[1] Mimiaga MJ, Helms DJ, Reisner SL, et al. Gonococcal, chlamydia, and syphilis infection positivity among MSM attending a large primary care clinic, Boston, 2003 to 2004. Sex Transm Dis 2009; 36: 507-11.

[2] Kent CK, Chaw JK, Wong W, et al. Prevalence of rectal, urethral, and pharyngeal chlamydia and gonorrhea detected in 2 clinical settings among men who have sex with men: San Francisco, California, 2003. Clin Infect Dis 2005; 41: 67-74.

[3] Ward H, Alexander S, Carder C, et al. The prevalence of lymphogranuloma venereum infection in men who have sex with men: results of a multicentre case finding study. Sex Transm Infect 2009; 85: 173-5.

[4] Frisch M, Smith E, Grulich A, Johansen C. Cancer in a populationbased cohort of men and women in registered homosexual partnerships. Am J Epidemiol 2003; 157: 966-72.

[5] Frisch M, Biggar RJ, Goedert JJ. Human papillomavirus-associated cancers in patients with human immunodeficiency virus infection and acquired immunodeficiency syndrome. $\mathrm{J}$ Natl Cancer Inst 2000; 92: 1500-10.

[6] Palefsky J. Human papillomavirus and anal neoplasia. Curr HIV/AIDS Rep 2008; 5: 78-85.
Buchacz K, Klausner JD, Kerndt PR, et al. HIV incidence among men diagnosed with early syphilis in Atlanta, San Francisco, and Los Angeles, 2004 to 2005. J Acquir Immune Defic Syndr 2008; 47: 234-40.

[8] Dougan S, Evans BG, Elford J. Sexually transmitted infections in Western Europe among HIV-positive men who have sex with men. Sex Transm Dis 2007; 34: 783-90.

[9] Emerson CR, Lynch A, Fox R, et al. The syphilis outbreak in Northern Ireland. Int J STD AIDS 2007; 18: 413-7.

[10] Simms I, Fenton KA, Ashton M, et al. The re-emergence of syphilis in the United Kingdom: the new epidemic phases. Sex Transm Dis 2005; 32: 220-6.

[11] Goh BT. Syphilis in adults. Sex Transm Infect 2005; 81: 448-52.

[12] Stary G, Stary A. Lymphogranuloma venereum outbreak in Europe. J Dtsch Dermatol Ges 2008; 6: 935-40.

[13] Urbanus AP, Schinkel M, deVries CJ, Coutinho HJC, van de Laar, TJW. The emergence of HCV among HIV-positive men who have sex with men is caused by high-risk sexual behaviour rather than HCV viral change. 18th International Society for STD Research (ISSTDR) 2009 (in press).

[14] Fenton KA, Lowndes CM. Recent trends in the epidemiology of sexually transmitted infections in the European Union. Sex Transm Infect 2004; 80: 255-63.

[15] Pearshouse R. Switzerland: statement on sexual transmission of HIV by people on ART. HIV AIDS Policy Law Rev 2008; 13: 378.

[16] Truong HM, Kellogg T, Klausner JD, et al. Increases in sexually transmitted infections and sexual risk behaviour without a concurrent increase in HIV incidence among men who have sex with men in San Francisco: a suggestion of HIV serosorting? Sex Transm Infect 2006; 82: 461-6.

[17] Moberg L, von Krogh G, Karlsson A, et al. Venereological study in Stockholm: 1 in 3 homosexual men had infections requiring treatment. Lakartidningen 1984; 81:2747-52.

[18] Morris SR, Klausner JD, Buchbinder SP, et al. Prevalence and incidence of pharyngeal gonorrhea in a longitudinal sample of men who have sex with men: the EXPLORE study. Clin Infect Dis 2006; 43: 1284-9.

[19] Cullberg M, Bratt G, Pettersson F, Karlsson A. Rectal and pharyngeal Chlamydia common among men who have sex with men. Lakartidningen 2009; 106: 24-7.

[20] Benn PD, Rooney G, Carder C, et al. Chlamydia trachomatis and Neisseria gonorrhoeae infection and the sexual behaviour of men who have sex with men. Sex Transm Infect 2007; 83: 106-12.

[21] Hansdotter F, Bratt G, Edlund M, et al. Increase of syphilis among men who have sex with men. Lakartidningen 2009; 106: 32-5.

[22] Lister NA, Chaves NJ, Phang CW, Smith A, Fairley CK. Clinical significance of questionnaire-elicited or clinically reported anorectal symptoms for rectal Neisseria gonorrhoeae and Chlamydia trachomatis amongst men who have sex with men. Sex Health 2008; 5: 77-82.

[23] Currie MJ, Martin SJ, Soo TM, Bowden FJ. Screening for chlamydia and gonorrhoea in men who have sex with men in clinical and non-clinical settings. Sex Health 2006; 3: 123-6.

[24] Lister NA, Smith A, Read T, Fairley CK. Testing men who have sex with men for Neisseria gonorrhoeae and Chlamydia trachomatis prior to the introduction of guidelines at an STD clinic in Melbourne. Sex Health 2004; 1: 47-50.

[25] Manavi K, McMillan A, Young H. The prevalence of rectal chlamydial infection amongst men who have sex with men attending the genitourinary medicine clinic in Edinburgh. Int J STD AIDS 2004; 15: 162-4.

[26] Annan NT, Sullivan AK, Nori A, et al. Rectal chlamydia--a reservoir of undiagnosed infection in men who have sex with men. Sex Transm Infect 2009; 85: 176-9.

[27] Ota KV, Fisman DN, Tamari IE, et al. Incidence and treatment outcomes of pharyngeal Neisseria gonorrhoeae and Chlamydia trachomatis infections in men who have sex with men: a 13-year retrospective cohort study. Clin Infect Dis 2009; 48: 1237-43.

[28] Tinmouth J, Gilmour MW, Kovacs C, et al. Is there a reservoir of sub-clinical lymphogranuloma venereum and non-LGV Chlamydia trachomatis infection in men who have sex with men? Int J STD AIDS 2008; 19: 805-9.

[29] Lister NA, Smith A, Tabrizi S, et al. Screening for Neisseria gonorrhoeae and Chlamydia trachomatis in men who have sex with men at male-only saunas. Sex Transm Dis 2003; 30: 886-9. 
[30] Satterwhite CL, Joesoef MR, Datta SD, Weinstock H. Estimates of Chlamydia trachomatis infections among men: United States. Sex Transm Dis 2008; 35(11 Suppl): S3-7.

[31] de Vries HJ, van der Bij AK, Fennema JS, et al. Lymphogranuloma venereum proctitis in men who have sex with men is associated with anal enema use and high-risk behavior. Sex Transm Dis 2008; 35: 203-8.

[32] Nieuwenhuis RF, Ossewaarde JM, Gotz HM, et al. Resurgence of lymphogranuloma venereum in Western Europe: an outbreak of Chlamydia trachomatis serovar 12 proctitis in The Netherlands among men who have sex with men. Clin Infect Dis 2004; 39: 9961003.

[33] Balmelli C, Gunthard HF. Gonococcal tonsillar infection--a case report and literature review. Infection 2003; 31: 362-5.

[34] Sathia L, Ellis B, Phillip S, Winston A, Smith A. Pharyngeal gonorrhoea - is dual therapy the way forward? Int J STD AIDS 2007; $18: 647-8$

[35] Albay DT, Mathisen GE. Head and neck manifestations of lymphogranuloma venereum. Ear Nose Throat J 2008; 87: 478-80.

[36] Sethi G, Allason-Jones E, Richens J, et al. Lymphogranuloma venereum presenting as genital ulceration and inguinal syndrome in men who have sex with men in London, UK. Sex Transm Infect 2009; 85: 165-70.

[37] Riemersma WA, van der Schee CJ, van der Meijden WI, Verbrugh HA, van Belkum A. Microbial population diversity in the urethras of healthy males and males suffering from nonchlamydial, nongonococcal urethritis. J Clin Microbiol 2003; 41: 1977-86.

[38] Abdolrasouli A, Amin A, Baharsefat M, Roushan A, Hemmati Y. Moraxella catarrhalis associated with acute urethritis imitating gonorrhoea acquired by oral-genital contact. Int J STD AIDS 2007; 18: 579-80.

[39] Bradshaw CS, Fairley CK, Lister NA, Chen S, Garland SM, Tabrizi SN. Mycoplasma genitalium in men who have sex with men at male-only saunas. Sex Transm Infect 2009 (in press).

[40] Davis TW, Goldstone SE. Sexually transmitted infections as a cause of proctitis in men who have sex with men. Dis Colon Rectum 2009; 52: 507-12.

[41] Quinn TC, Goodell SE, Mkrtichian E, et al. Chlamydia trachomatis proctitis. N Engl J Med 1981; 305: 195-200.

[42] Klotz SA, Drutz DJ, Tam MR, Reed KH. Hemorrhagic proctitis due to lymphogranuloma venereum serogroup L2: diagnosis by fluorescent monoclonal antibody. N Engl J Med 1983; 308: 1563-5.

[43] Hamill M, Benn P, Carder C, et al. The clinical manifestations of anorectal infection with lymphogranuloma venereum (LGV) $v s$ non-LGV strains of Chlamydia trachomatis: a case-control study in homosexual men. Int J STD AIDS 2007; 18: 472-5.

[44] Sohn N, Robilotti JG, Jr. The gay bowel syndrome: a review of colonic and rectal conditions in 200 male homosexuals. Am J Gastroenterol 1977; 67: 478-84.

[45] McMillan A, van Voorst Vader PC, de Vries HJ. The 2007 European Guideline (International Union against Sexually Transmitted Infections/World Health Organization) on the management of proctitis, proctocolitis and enteritis caused by sexually transmissible pathogens. Int J STD AIDS 2007; 18: 51420.

[46] Goodell SE, Quinn TC, Mkrtichian E, Schuffler MD, Holmes KK, Corey L. Herpes simplex virus proctitis in homosexual men. Clinical, sigmoidoscopic, and histopathological features. N Engl J Med 1983; 308: 868-71.

[47] Francis SC, Kent CK, Klausner JD, et al. Prevalence of rectal Trichomonas vaginalis and Mycoplasma genitalium in male patients at the San Francisco STD clinic, 2005-2006. Sex Transm Dis $2008 ; 35: 797-800$.

[48] McMillan A, Young H. Clinical correlates of rectal gonococcal and chlamydial infections. Int J STD AIDS 2006; 17: 387-90.

[49] Richardson D, Goldmeier D. Lymphogranuloma venereum: an emerging cause of proctitis in men who have sex with men. Int J STD AIDS 2007; 18: 11-4.

[50] Gotz HM, Ossewaarde JM, Nieuwenhuis RF, et al. A cluster of lymphogranuloma venereum among homosexual men in Rotterdam with implications for other countries in Western Europe. Ned Tijdschr Geneeskd 2004; 148: 441-2.

[51] van den Bos RR, van der Meijden WI. Persistent high-risk sexual behaviour in men who have sex with men after symptomatic lymphogranuloma venereum proctitis. Int J STD AIDS 2007; 18: 715-6.
[52] Ashton M, Sopwith W, Clark P, McKelvey D, Lighton L, Mandal D. An outbreak no longer: factors contributing to the return of syphilis in Greater Manchester. Sex Transm Infect 2003; 79: 291-3.

[53] Fenton KA, Breban R, Vardavas R, et al. Infectious syphilis in high-income settings in the 21 st century. Lancet Infect Dis 2008; 8 : 244-53.

[54] Doherty L, Fenton KA, Jones J, et al. Syphilis: old problem, new strategy. BMJ 2002; 325: 153-6.

[55] Cronin M, Domegan L, Thornton L, et al. The epidemiology of infectious syphilis in the Republic of Ireland. Euro Surveill 2004; 9: 14-7.

[56] Chen JL, Callahan DB, Kerndt PR. Syphilis control among incarcerated men who have sex with men: public health response to an outbreak. Am J Public Health 2002; 92: 1473-4.

[57] Huhn GD, McIntyre AF, Broad JM, et al. Factors associated with newly diagnosed HIV among persons with concomitant sexually transmitted diseases. Sex Transm Dis 2008; 35: 731-7.

[58] Buchacz K, Patel P, Taylor M, et al. Syphilis increases HIV viral load and decreases CD4 cell counts in HIV-infected patients with new syphilis infections. AIDS 2004; 18: 2075-9.

[59] Goh BT, van Voorst Vader PC. European guideline for the management of syphilis. Int J STD AIDS 2001; 12(Suppl 3): 14-26.

[60] Fleming DT, Wasserheit JN. From epidemiological synergy to public health policy and practice: the contribution of other sexually transmitted diseases to sexual transmission of HIV infection. Sex Transm Infect 1999; 75: 3-17.

[61] French P, Gomberg M, Janier M, Schmidt B, van Voorst Vader P, Young H. IUSTI: 2008 European Guidelines on the Management of Syphilis. Int J STD AIDS 2009; 20: 300-9.

[62] Marra CM, Maxwell CL, Smith SL, et al. Cerebrospinal fluid abnormalities in patients with syphilis: association with clinical and laboratory features. J Infect Dis 2004; 189: 369-76.

[63] Handsfield HH. Hepatitis A and B immunization in persons being evaluated for sexually transmitted diseases. Am J Med 2005; 118(Suppl 10A): 69S-74S.

[64] Christenson B, Brostrom C, Bottiger M, et al. An epidemic outbreak of hepatitis A among homosexual men in Stockholm. Hepatitis A, a special hazard for the male homosexual subpopulation in Sweden. Am J Epidemiol 1982; 116: 599-607.

[65] O'Riordan M, Goh L, Lamba H. Increasing hepatitis A IgG prevalence rate in men who have sex with men attending a sexual health clinic in London: implications for immunization policy. Int $\mathrm{J}$ STD AIDS 2007; 18: 707-10.

[66] Mazick A, Howitz M, Rex S, et al. Hepatitis A outbreak among MSM linked to casual sex and gay saunas in Copenhagen, Denmark. Euro Surveill 2005; 10: 111-4.

[67] Piot P, Goilav C, Kegels E. Hepatitis B: transmission by sexual contact and needle sharing. Vaccine 1990; 8: S37-40; discussion S1-3

[68] Ravenholt RT. Role of hepatitis B virus in acquired immunodeficiency syndrome. Lancet 1983; 2: 885-6.

[69] Ostrow DG, Altman NL. Sexually transmitted diseases and homosexuality. Sex Transm Dis 1983; 10: 208-15

[70] Chang MH. Cancer prevention by vaccination against hepatitis B. Recent Results Cancer Res 2009; 181: 85-94.

[71] Yee LJ, Rhodes SD. Understanding correlates of hepatitis B virus vaccination in men who have sex with men: what have we learned? Sex Transm Infect 2002; 78: 374-7.

[72] European Association For The Study Of The L. EASL Clinical Practice Guidelines: management of chronic hepatitis B. J Hepatol 2009; 50: 227-42.

[73] van de Laar T, Pybus O, Bruisten S, et al. Evidence of a large, international network of HCV transmission in HIV-positive men who have sex with men. Gastroenterology 2009; 136: 1609-17.

[74] Pelgrom JM, Vogelaers D, Colle I. Hepatitis C-seroconversion within three to six months after having contracted clinical syphilis and/or lymphogranuloma venereum rectitis in five homosexually active, HIV seropositive men. Acta Clin Belg 2008; 63: 335-8.

[75] Larsen C, Pialoux G, Salmon D, et al. Prevalence of hepatitis C and hepatitis B infection in the HIV-infected population of France, 2004. Euro Surveill 2008; 13: 18888.

[76] Giraudon I, Ruf M, Maguire H, et al. Increase in diagnosed newly acquired hepatitis $\mathrm{C}$ in HIV-positive men who have sex with men across London and Brighton, 2002-2006: is this an outbreak? Sex Transm Infect 2008; 84: 111-5. 
[77] Ghany MG, Strader DB, Thomas DL, Seeff LB. Diagnosis, management, and treatment of hepatitis $\mathrm{C}$ : an update. Hepatology 2009; 49: 1335-74.

[78] Frazer IH, Cox JT, Mayeaux EJ, Jr., et al. Advances in prevention of cervical cancer and other human papillomavirus-related diseases. Pediatr Infect Dis J 2006; 25(2 Suppl): S65-81.

[79] Nasman A, Attner P, Hammarstedt L, et al. Incidence of human papillomavirus (HPV) positive tonsillar carcinoma in Stockholm, Sweden: an epidemic of viral-induced carcinoma? Int J Cancer 2009; 125: 362-6.

[80] Vajdic CM, van Leeuwen MT, Jin F, et al. Anal human papillomavirus genotype diversity and co-infection in a community-based sample of homosexual men. Sex Transm Infect 2009 (in press).

[81] Chin-Hong PV, Berry JM, Cheng SC, et al. Comparison of patientand clinician-collected anal cytology samples to screen for human papillomavirus-associated anal intraepithelial neoplasia in men who have sex with men. Ann Intern Med 2008; 149: 300-6.

[82] de Pokomandy A, Rouleau D, Ghattas G, et al. Prevalence, clearance, and incidence of anal human papillomavirus infection in HIV-infected men: the HIPVIRG cohort study. J Infect Dis 2009; 199: 965-73.

[83] Kreuter A, Wieland U. Human papillomavirus-associated diseases in HIV-infected men who have sex with men. Curr Opin Infect Dis 2009; 22: 109-14.

[84] Hoots BE, Palefsky JM, Pimenta JM, Smith JS. Human papillomavirus type distribution in anal cancer and anal intraepithelial lesions. Int J Cancer 2009; 124: 2375-83.

[85] Chin-Hong PV, Vittinghoff E, Cranston RD, et al. Age-related prevalence of anal cancer precursors in homosexual men: the EXPLORE study. J Natl Cancer Inst 2005; 97: 896-905.

[86] Kreuter A, Brockmeyer NH, Weissenborn SJ, et al. Penile intraepithelial neoplasia is frequent in HIV-positive men with anal dysplasia. J Invest Dermatol 2008; 128: 2316-24.

[87] Abramowitz L, Benabderrahmane D, Ravaud P, et al. Anal squamous intraepithelial lesions and condyloma in HIV-infected heterosexual men, homosexual men and women: prevalence and associated factors. AIDS 2007; 21: 1457-65.

[88] D'Souza G, Wiley DJ, Li X, et al. Incidence and epidemiology of anal cancer in the multicenter AIDS cohort study. J Acquir Immune Defic Syndr 2008; 48: 491-9.

[89] Orlando G, Tanzi E, Beretta R, et al. Human papillomavirus genotypes and anal-related lesions among HIV-1-infected men in Milan, Italy. J Acquir Immune Defic Syndr 2008; 47: 129-31.

[90] Garnett GP, Kim JJ, French K, Goldie SJ. Modelling the impact of HPV vaccines on cervical cancer and screening programmes. Vaccine 2006; 24(Suppl 3): S3178-86.

[91] De Vuyst H, Clifford GM, Nascimento MC, Madeleine MM, Franceschi S. Prevalence and type distribution of human papillomavirus in carcinoma and intraepithelial neoplasia of the vulva, vagina and anus: a meta-analysis. Int J Cancer 2009; 124: 1626-36.
[92] Pitts MK, Fox C, Willis J, Anderson J. What do gay men know about human papillomavirus? Australian gay men's knowledge and experience of anal cancer screening and human papillomavirus. Sex Transm Dis 2007; 34: 170-3.

[93] Tider DS, Parsons JT, Bimbi DS. Knowledge of human papillomavirus and effects on sexual behaviour of gay/bisexual men: a brief report. Int J STD AIDS 2005; 16: 707-8.

[94] Simatherai D, Bradshaw CS, Fairley CK, Bush M, Heley S, Chen MY. What men who have sex with men think about the human papillomavirus vaccine. Sex Transm Infect 2009; 85: 148-9.

[95] Cohen MS, Hoffman IF, Royce RA, et al. Reduction of concentration of HIV-1 in semen after treatment of urethritis: implications for prevention of sexual transmission of HIV-1. AIDSCAP Malawi Research Group. Lancet 1997; 349: 1868-73.

[96] Schwarcz S, Weinstock H, Louie B, et al. Characteristics of persons with recently acquired HIV infection: application of the serologic testing algorithm for recent HIV seroconversion in 10 US cities. J Acquir Immune Defic Syndr 2007; 44: 112-5.

[97] Zetola NM, Bernstein KT, Wong E, Louie B, Klausner JD. Exploring the relationship between sexually transmitted diseases and HIV acquisition by using different study designs. J Acquir Immune Defic Syndr 2009; 50: 546-51.

[98] Garvey LJ, Roberts C, Smith A. Confirmed new HIV diagnoses in men who have sex with men after episodes of rectal gonorrhoea. Int J STD AIDS 2009; 20: 144.

[99] Bratt G, Hejdeman B. Sexually transmitted infections increase the risk of HIV: a survey among men who have sex with men shows a strong connection. Lakartidningen 2006; 103: 1438-9.

[100] Scott KC, Philip S, Ahrens K, Kent CK, Klausner JD. High prevalence of gonococcal and chlamydial infection in men who have sex with men with newly diagnosed HIV infection: an opportunity for same-day presumptive treatment. J Acquir Immune Defic Syndr 2008; 48: 109-12.

[101] Helms DJ, Weinstock HS, Mahle KC, et al. HIV testing frequency among men who have sex with men attending sexually transmitted disease clinics: implications for HIV prevention and surveillance. $\mathrm{J}$ Acquir Immune Defic Syndr 2009; 50: 320-6.

[102] Craib KJ, Meddings DR, Strathdee SA, et al. Rectal gonorrhoea as an independent risk factor for HIV infection in a cohort of homosexual men. Genitourin Med 1995; 71: 150-4.

[103] Joyee AG, Thyagarajan SP, Reddy EV, Venkatesan C, Ganapathy M. Genital chlamydial infection in STD patients: its relation to HIV infection. Indian J Med Microbiol 2005; 23: 37-40.

[104] Rieg G, Lewis RJ, Miller LG, Witt MD, Guerrero M, Daar ES. Asymptomatic sexually transmitted infections in HIV-infected men who have sex with men: prevalence, incidence, predictors, and screening strategies. AIDS Patient Care STDS 2008; 22: 947-54.

[105] Branson BM, Handsfield HH, Lampe MA, et al. Revised recommendations for HIV testing of adults, adolescents, and pregnant women in health-care settings. MMWR Recomm Rep 2006; 55: 1-17. 